D I c E latindex @ideAs Econpapers ODialnet $\stackrel{\text { InDICEs }}{\equiv}$ MIAR Sucupira

\title{
EL ESQUIROLAJE EN LA EMPRESA DEL SIGLO XXI. REPASO JURISPRUDENCIAL DEL CASO ESPAÑOL
}

\author{
José Enrique Ruiz Saura \\ Investigador predoctoral. Universidad de Murcia, España \\ Correspondencia: jsaura.ruiz@gmail.com
}

Para citar este artículo puede utilizar el siguiente formato:

José Enrique Ruiz Saura (2021): "El esquirolaje en la empresa del siglo XXI. Repaso jurisprudencial del caso español”, Revista DELOS, (Especial noviembre 2021). En línea:

https://doi.org/10.51896/DELOS/KJGA8564

\section{RESUMEN}

En las últimas décadas, la doctrina científica y jurisprudencial ha ido concretando los límites legales de las nuevas prácticas empresariales dirigidas a anular los efectos del ejercicio de la huelga, todas ellas comprendidas en el concepto de esquirolaje. Dado que la actual regulación de este derecho fundamental es escasa y data del año 1977, para poder determinar con precisión el criterio judicial aplicable ante realidades laborales novedosas, ha de estudiarse minuciosamente la evolución y la consolidación de la jurisprudencia acaecida a raíz de la entrada en el escenario laboral de fenómenos como la externalización de servicios, la automatización de procesos o la gestión algorítmica de los recursos humanos. Consecuentemente, en este trabajo se ha procedido a la recopilación y análisis exhaustivo de las resoluciones más relevantes que el Tribunal Constitucional, el Tribunal Supremo y distintos Tribunales Superiores de Justicia han emitido en los últimos años. De ello, puede extraerse que los tribunales han pasado de censurar únicamente la sustitución de huelguistas por trabajadores ajenos a la empresa (esquirolaje externo) a declarar contrarios a Derecho otros tipos no recogidos expresamente en la norma, como es la sustitución de huelguistas por trabajadores pertenecientes a empresas contratistas, más recientemente, sustituir la labor de los trabajadores ausentes mediante el empleo de instrumentos tecnológicos ("esquirolaje tecnológico").

Palabras clave: huelga, derecho fundamental, conflicto colectivo, esquirolaje externo, subcontratación, esquirolaje tecnológico.

\section{SIROLEYING IN THE 21 ${ }^{\text {st }}$ CENTURY COMPANY. LEGAL REWIEW}

\section{ABSTRACT}

In recent decades, scientific and jurisprudential doctrine has been specifying the legal limits of new business practices aimed at nullifying the effects of the exercise of the strike, all of them included in the concept of scab. Given that the current regulation of this fundamental right is scarce and dates from 1977, in order to accurately determine the applicable judicial criteria in the face of novel labor 
realities, the evolution and consolidation of the jurisprudence that occurred as a result of the entry into the labor scene of phenomena such as the outsourcing of services, the automation of processes or the algorithmic management of human resources. Consequently, in this work we have proceeded to the compilation and exhaustive analysis of the most relevant resolutions that the Constitutional Court, the Court Supreme and different Superior Courts of Justice have issued in recent years. From this, it can be deduced that the courts have gone from censuring only the replacement of strikers by workers outside the company (external scab) to declaring contrary to the Law other types not expressly included in the norm, such as the replacement of strikers by workers belonging to more recently, contracting companies substitute the work of absent workers through the use of technological instruments ("technological scab").

Keywords: strike, fundamental right, collective dispute, external scab, subcontracting, technological scab.

\section{INTRODUCCIÓN}

El derecho de huelga es el único de los derechos fundamentales recogidos en la Constitución Española (CE) que no ha sido desarrollado mediante ley orgánica en los más de cuarenta años transcurridos desde la aprobación de la carta magna. Así mismo, el único texto normativo que regula con una cierta concreción el ejercicio de este derecho, el Real Decreto-Ley 17/1977, de 4 de marzo, sobre relaciones de trabajo (RDL 17/77), es de naturaleza preconstitucional. De tal forma que, algunos artículos pasaron a ser incompatibles con la CE cuando ésta fue aprobada. Para hacer frente a esta anomalía legal, el Tribunal Constitucional, en su sentencia nํ11/1981, de 8 de abril, acometió la importante función de "depurar" al RDL 17/77 de todos los elementos inconstitucionales que albergaba inicialmente. No obstante, lo deseable por el constituyente al dictar esa resolución no era habilitar que la antedicha normativa mantuviera su vigencia en el largo plazo, sino sólo transitoriamente hasta la promulgación de una ley orgánica de huelga, lo cual no tuvo lugar como ya hemos señalado.

Como consecuencia de lo anterior, determinadas sentencias del Tribunal Constitucional (TC), del Tribunal Supremo (TS) e, incluso, de la Audiencia Nacional (AN) y determinados Tribunales Superiores de Justicia (TSJs), han servido para completar los vacíos en la regulación del derecho de huelga que periódicamente se han tenido que afrontar en las últimas décadas. Partiendo de ello, este texto pretende clarificar cómo se está delimitando en la actualidad la figura jurídica del esquirolaje, como vulneración del derecho fundamental de huelga, en un contexto cambiante condicionado por nuevas formas empresariales y de organización del trabajo. Se incide en qué nuevas prácticas empresariales serían atentatorias contra el ejercicio de la huelga, tratando de observar la tendencia que puede seguirse en los años venideros. Concretamente, en las siguientes líneas, abordaremos cómo ha evolucionado el esquirolaje externo ante el abanico de posibilidades que le ha abierto los nuevos mecanismos de descentralización de la producción de bienes y servicios que se han generalizado en las últimas décadas, y cuál ha sido la reacción de la doctrina ante esta coyuntura. 
Así mismo, analizaremos el papel de la robotización, automatización de procesos y, en general, de la innovación tecnológica en los contextos de conflictividad laboral, deteniéndonos en las diversas consideraciones que han llevado a cabo los tribunales.

No obstante, como punto de partida, recordaremos someramente los conceptos de esquirolaje externo, interno y tecnológico según lo dispuesto en el ordenamiento jurídico y la doctrina de nuestro país.

En primer lugar, se considera esquirolaje externo el supuesto de sustitución de trabajadores huelguistas prohibido expresamente en el art. 6.5 del RDL 17/77, es decir, cuando quienes realizan las sustituciones no formaban parte de la plantilla de la empresa o, en su caso, del centro de trabajo en el momento de iniciarse la huelga. Como ha indicado López-Tamés (2014): "El recurso a nuevos trabajadores, que se contratan precisamente para que desarrollen la actividad abandonada por los que secundan un conflicto, sería la manifestación más clara, la 'primera forma' de privar de eficacia a la huelga"1.

Por su parte, el esquirolaje interno tiene lugar cuando, en un contexto de huelga, el empresario recurre al personal contratado no huelguista para reasignarle tareas que habitualmente no realiza y que son propias de quienes sí han secundado esa medida. En este caso, como señala López-Tamés (2014), dicha práctica supondría una superación de los límites al ejercicio del "ius variandi", puesto que el mismo sería realizado con la finalidad de desactivar la presión producida por el paro en el trabajo y, por tanto, atentaría contra el recíproco deber de lealtad y buena fe que sigue siendo exigible durante la huelga.

Además de los dos tipos de esquirolaje habituales que hemos analizado en páginas anteriores, el externo y el interno, la doctrina del TS ha creado más recientemente la figura del llamado "esquirolaje tecnológico". Éste puede considerarse una evolución del interno, pues consiste en recurrir a medios técnicos preexistentes en la empresa para cubrir provisionalmente la realización de tareas que deja de asumir la persona huelguista."

\section{METODOLOGÍA}

\section{Materiales y métodos}

El objeto de estudio ha abarcado, aproximadamente, medio centenar de resoluciones judiciales emitidas por el TC, el TS, la AN y diversos TSJs a lo largo de los últimos cuarenta años. Para mayor claridad, al final de este trabajo, se presenta como anexo un listado en el que todas ellas aparecen agrupadas en base a dos criterios: el órgano judicial del cual emanan y un orden cronológico ascendente, empezando por la más antigua para terminar con la más reciente. Para obtener el material utilizado, hemos utilizado una serie de bases de datos de probada solvencia, como son la del Consejo General del Poder Judicial (CENDOJ), Aranzadi o Vlex.

\footnotetext{
${ }^{1}$ LÓPEZ-TAMÉS IGLESIAS, R., "Significativos cercanos pronunciamientos sobre la huelga", op. cit., página 116.
} 
El criterio seguido para seleccionar y detenernos en la revisión exhaustiva de cada una de las sentencias y autos empleados, ha consistido en partir de la premisa de que las mismas aporten una fundamentación jurídica de cierta relevancia en lo referente a la regulación del derecho de huelga. Nos hemos basado, por un lado, en seleccionar y extraer lo más interesante de la doctrina científica en materia de esquirolaje y vulneración de la huelga como derecho fundamental por parte del empleador. $Y$ en su mayor parte, además, en investigar la jurisprudencia que guarde mayor relación con el objeto de estudio (especialmente, la más reciente y novedosa), con la finalidad de resaltar todo aquello que resulte innovador desde el punto de vista interpretativo.

La metodología seguida en la investigación y obtención de datos es la documentación, por tanto, se trata de una línea de estudio de índole cualitativa. Sin duda, es la forma de proceder más pertinente para, como ha ocurrido en nuestro caso, lograr una interpretación de la realidad jurídica atendiendo al contexto social y laboral cambiante que se da en la actualidad.

\section{RESULTADOS}

\section{Evolución del esquirolaje externo ante las nuevas formas de externalizar la producción}

En el tenor literal del art. 6.5 del RDL 17/77, es decir, en el precepto normativo donde queda expresamente prohibida la realización de esquirolaje externo, se hace referencia a los "trabajadores dependientes y por cuenta ajena", no haciéndose alusión a contratistas o trabajadores autónomos. A pesar de ello, es mayoritaria la doctrina que entiende que este precepto debe enfocarse a la luz de la finalidad pretendida por la norma, es decir, censurar la sustitución de unos trabajadores en huelga por otros que no tenían asignado realizar esa tarea específica antes de iniciarse el conflicto (Sala, 2013). De hecho, se llega aún más lejos, puesto que también se considera contraria al derecho fundamental de huelga la práctica empresarial consistente en reasignar a otros centros de trabajo de la misma empresa encargos o tareas que, inicialmente, eran propios del centro de trabajo que paraliza su actividad. Incluso, se determinó que era contraria a Derecho la práctica consistente en aumentar la producción de otros centros de trabajo que no se encuentran en huelga, para abastecer los puntos de distribución de la empresa que se encuentra en huelga, siendo posteriormente distribuidos por transportistas autónomos a los supermercados o clientes (STSJ Cataluña de 24 de abril de 2015).

En la actualidad, la jurisprudencia aboga claramente por esta interpretación. En este sentido, destaca la STS de 20 de abril de 2015, rec. núm. 354/2014 (caso Grupo Coca-Cola). Concretamente, en esa ocasión se declaró que suponía una vulneración del derecho de huelga que, en aras a compensar la falta de producción provocada por la paralización de la actividad llevada a cabo por los trabajadores en su planta embotelladora de Fuenlabrada (Madrid), la mercantil Coca Cola Iberian Partners (CCIP) recurriese de forma hasta ese momento inusual a prácticas de colaboración entre los integrantes del grupo de empresas. Cabe señalar que, cuando se desencadenó el conflicto abordado en la referida sentencia, el Grupo Coca-Cola tenía una serie de centros de trabajo distribuidos a lo largo de la geografía nacional. Así mismo, la producción venía estando estructurada de tal manera 
que cada centro tenía asignado un área territorial claramente delimitada para abastecer la fabricación, distribución y ventas al consumidor del producto final. Por tanto, la paralización de la actividad productiva en la planta de Fuenlabrada suponía que, en la zona de Madrid, iba a darse un desabastecimiento ("un agotamiento de existencias previsto por la propia empresa para el día 20 de febrero").

Ante tal situación, el Grupo Coca-Cola reaccionó rompiendo el sistema de organización de la producción por territorios descrito, pasando a surtir al centro de Fuenlabrada de productos elaborados en las plantas embotelladoras de otros lugares y, a continuación, habilitar a este centro para continuar su distribución en Madrid de ese producto final proveído desde otros lugares. Estos hechos tuvieron lugar en un contexto de plena huelga de los trabajadores de esa planta y durante el desarrollo del complejo periodo de negociación de despidos colectivos. Sentado todo lo anterior como hechos constatados, el TS estimó probado que, con la finalidad de no provocar un desabastecimiento del producto, "en la semana del 14 de febrero habían entrado en aquella plataforma logística entre cinco y seis grandes camiones y que el día 18 de febrero entraron trece camiones más también con productos fabricados en otras plantas, uno procedente de A Coruña, seis procedentes de Sevilla y seis de Burgos". Todo ello, fue para el tribunal un ejercicio antisindical del poder de organización de CCIP en tanto que pretendía eliminar los efectos de la huelga puesta en marcha legítimamente por los trabajadores de esa planta.

En cambio, la prohibición legal de esquirolaje no impide, según la jurisprudencia, que las empresas que tengan suscrita una contrata o subcontrata con una empresa contratista en huelga puedan utilizar los servicios de otra.

El derecho fundamental de huelga no incluye en su contenido el poder exigir de un tercero ajeno a la relación laboral entre empresa y trabajadores huelguistas que sufra también una reducción en su proceso productivo 0 en los servicios que presta (....). Los trabajadores que se encuentren en huelga no pueden imponer a la empresa principal que deje desatendidos (aquellos servicios) cuya asistencia no pueda dispensarse dentro de los límites impuestos como servicios mínimos de huelga. Ni la ley ofrece base para tal exigencia ni vemos que ello pudiera ser posible, en tanto en cuanto esa extensión del derecho de huelga frente a terceros alcanzaría no solo al empresario de los titulares del derecho de huelga sino también a otros sujetos distintos" (STSJ del País Vasco de 4 de julio de 2000).

No obstante, hay un supuesto excepcional en el que la subcontratación de productos o servicios por parte de la empresa cliente sería considerada una conducta vulneradora del derecho de huelga de la plantilla de la empresa subcontratista. Se trata de aquellos casos en los que exista una especial vinculación entre las empresas intervinientes y la afectada por la huelga que justifique la 
obligación de aquellas de respetar la huelga y en su caso contrario, la atribución de responsabilidad. En este sentido, debe destacarse por su especial importancia la STS 11 de febrero de 2015, en la que se entró a conocer y resolver el controvertido caso de la empresa PRESSPRINT. La referida mercantil es una empresa del Grupo PRISA que asume la encomienda de la impresión de varios periódicos de dicho grupo editorial. Durante la huelga de los trabajadores de PRESSPRINT y ante la imposibilidad de la empresa de prestar su servicio auxiliar al grupo PRISA, ésta contrató con otras empresas la impresión de los periódicos de modo que éstos fueron impresos y repartidos en los puntos de venta con total normalidad. En vista de ello, el Alto Tribunal señaló lo siguiente:

En aplicación de la doctrina contenida en la STC 75/2010, se ha de concluir que la conducta de las empresas editoras demandadas ha vulnerado los derechos de libertad sindical y de huelga de los trabajadores de PRESSPINT. A este respecto hay que señalar que, si bien es cierto que dichas entidades mercantiles no mantienen relación laboral directa con los trabajadores huelguistas, ya que estos prestan servicios a PRESSPINT, en virtud de los contratos de trabajo suscritos con la citada empresa, no es menos cierto que la actuación de dichas empresas, consistente en contratar con las empresas IMPRINTSA, INDUGRAF, BEPSA, PRINTOLID, e IMPRENTA NORTE la impresión de sus publicaciones durante los días en que los trabajadores de PRESSPINT estuvieron de huelga, ha incidido seriamente en los efectos y repercusión de la huelga. Hay, por tanto, una "especial vinculación" entre los trabajadores huelguistas que prestan sus servicios en la empresa contratista y las empresas principales ya que están vinculados directamente a la actividad productiva de dichas empresas por ser las destinatarias últimas de su actividad laboral. Por dicho motivo la efectividad de sus derechos fundamentales, entre ellos el derecho de huelga, puede verse afectado por la actuación de los empresarios principales $y$, en consecuencia, habrán de ser protegidos frente a estas posibles actuaciones vulneradoras del derecho de huelga, ya que en caso contrario se produciría una situación de desamparo de los trabajadores.

No obstante, en contraposición a lo anterior, la STS no 961/2016, de 16 de noviembre, puso de relieve determinados matices a tener en cuenta a la hora de analizar la referida casuística. Específicamente, en esta última sentencia, como ya adelantamos en párrafos anteriores, se resaltó la importancia de la existencia de vínculos entre la empresa cliente y la nueva empresa contratista como elemento decisivo para hallarnos o no ante un supuesto de esquirolaje externo:

El hecho de que las empresas clientes contrataran con otras 
durante los paros el servicio de andamiaje que habitualmente les prestaba Altrad no supone una vulneración del derecho de huelga, ya que entre dichas empresas no existía una vinculación especial ni formaban un grupo de empresas con Altrad. No se aplica, por tanto, la doctrina recogida en las SSTS de 11 de febrero de 2015, rec. núm. 95/2014 (caso Grupo Prisa) y de 20 de abril de 2015, rec. núm. 354/2014 (caso Coca-Cola). La Actuación del Altrad consistió únicamente en comunicar a todos sus clientes que no podían realizar los trabajos comprometidos durante la realización de la huelga por sus trabajadores.

$\ldots / \ldots$

(...) no existe una vinculación que justifique hacer responder a Altrad Rodisola de una conducta en la que no ha participado y en la que no ha podido intervenir para tomar la decisión. La condición de clientes de Dow y Basell tampoco determinan ninguna vinculación especial que pueda condicionar la decisión de dichas empresas clientes de contratar trabajos con otras empresas de la competencia durante la huelga y tampoco las referidas empresas clientes forman un grupo de empresas con Altrad.

Es un caso bien distinto al de la sentencia de 11/2/15 (Grupo Prisa), en donde la parte demandante sostenía esa especial vinculación, ya que los recurrentes habían demandado, no sólo a la empresa en la que se convocó la huelga, PRESSPRINT S.L., sino también a EDICIONES EL PAÍS S.L., DIARIO AS S.L. y ESTRUCTURA GRUPO DE ESTUDIOS ECONÓMICOS S.A., todas ellas pertenecientes al GRUPO PRISA, siendo el único socio de PRESSPRINT S.L., EDICIONES EL PAÍS S.L., que cuenta con el $100 \%$ de su capital social y actúa como administrador único y la empresa PRESSPRINT S.L. tiene al Grupo PRISA como cliente mayoritario en un porcentaje superior al $70 \%$.

Además, en estos casos, si durante la huelga del personal de una empresa contratista o subcontratista, a resultas de la ocupación de los locales de la empresa principal por parte de los huelguistas se derivaran perjuicios para ésta, en la medida en que corresponde a la empresa contratista la obligación de ordenar el desalojo, no hay duda de que la empresa principal, además de rescindir en su caso la contrata, podría exigir a la empresa contratista una indemnización.

De tratarse de una contrata de servicios que cubriera los servicios mínimos exigibles para una empresa principal que realiza servicios esenciales para la comunidad en caso de huelga de su 
propio personal, la responsabilidad de garantizar los servicios mínimos durante la huelga del personal de la empresa contratista o subcontratistas pertenece a la empresa principal y no a estas últimas. En este sentido, la disparidad de pronunciamientos dados en las dos sentencias precedentes, se entiende mejor atendiendo al alcance dado al concepto "especial vinculación", que es un término ligado con la dinámica de funcionamiento de los grupos de empresas de carácter jerárquico. Esta noción se basa en la concurrencia de dos elementos diferenciales: alto grado de integración entre las actividades productivas de las empresas, y el sometimiento de todas las empresas a la influencia dominante de una de ellas.

Es por ello que la jurisprudencia comenzó a entender que, desde bases constitucionales, era ajustado a Derecho extender a las personas trabajadoras las garantías del derecho de huelga. Dada su especial relevancia, también se ha hecho hincapié en la doble vinculación (orgánica y funcional) entre empresa cliente y subcontrata. Por ello, el Tribunal Supremo ha establecido que, en actividades productivas o de prestaciones de servicios donde exista una cierta fragmentación empresarial, "cuya actuación coordinada puede repercutir sobre algunos derechos de los trabajadores de cualquiera de las empresas del grupo", también "existe una obligación conjunta de respeto de los derechos de los trabajadores, singularmente de los colectivos, alguna de las cuales se desprende directamente de las propias previsiones legales" (Vicente, 2019).

Más recientemente, el Alto Tribunal se ha reafirmado en el criterio de considerar que, cualquier contratación externa de servicios en el supuesto de que una subcontrata vea paralizada su actividad, se situará dentro o fuera de la licitud atendiendo a que haya o no "especial vinculación" entre empresa principal y auxiliar de servicios. Un primer ejemplo de ello, lo encontramos en la STS no 885/2018, de 3 de octubre (asunto Grupo Zeta), donde como en el caso de Grupo PRISA, tiene lugar una huelga planteada en una empresa del mismo grupo mercantil que la destinataria de sus servicios, siendo el cometido de los huelguistas la impresión de las publicaciones de otras empresas del referido grupo. Así mismo, otra resolución equiparable a la anterior en el supuesto de hecho y la fundamentación jurídica, fue la STS no 888/2018, de 3 de octubre. En el caso de autos, la empresa contratista (Andaluprint) también es miembro del mismo grupo empresarial que ABC Sevilla, la empresa principal. Ocurre que la representación de los trabajadores convocó una huelga indefinida en enero de 2015 con seguimiento mayoritario de la plantilla, todo ello como respuesta a la decisión empresarial de cerrar Andaluprint. Seguidamente, ABC Sevilla encargó la impresión del periódico y sus suplementos a dos empresas subcontratistas ajenas al grupo Vocento (Iniciativas de Publicaciones e Inspección SL y Recoprint SL).

En esta sentencia, se hace un somero repaso de las distintas resoluciones dictadas en relación a esta cuestión. De tal forma que distingue, por un lado, los supuestos de subcontratación ordinaria, esto es, aquéllos en los que las relaciones interempresariales se limitan a la vertiente estrictamente mercantil sin estrategias conjuntas de producción o comerciales, y por otro, aquellos otros casos en los que la externalización del servicio es asignada a empresas del mismo grupo empresarial. Llegados a este punto, cabe resaltar que el análisis de esta última sentencia llevado a 
cabo por Vicente $(2019)^{2}$, arrojó las siguientes conclusiones sobre las repercusiones que la misma tiene en la consolidación de la doctrina sobre el esquirolaje dado en escenarios de descentralización productiva:

La jurisprudencia pues, queda claramente establecida diferenciando estos dos supuestos. En el primer caso, y en atención a que las relaciones interempresariales se limitan a la vertiente estrictamente mercantil sin condicionantes de estrategias conjuntas de producción, comerciales o de otro tipo, el Tribunal concluye en la ausencia de vulneración del derecho de huelga pues no "(...) exist(e) ninguna especial vinculación, ni ningún otro tipo de circunstancia que a la empresa principal le obligara a respetar la huelga $y$, consecuentemente, a no contratar con otros las obras que ya tenía contratadas (...)". Por el contrario, sí existe vulneración del derecho de huelga por la conducta de la empresa principal en los supuestos en los que existen relaciones societarias entre la empresa principal y la empresa contratista. Aun partiendo de que se trata de una opción legítima amparada en el principio de libertad de empresa (art. $38 \mathrm{CE}$ ), y con independencia de que no resulte aplicable la doctrina de comunicación de responsabilidades derivada de la doctrina del "levantamiento del velo societario", para el Tribunal Supremo esta forma de organización empresarial presenta indudables ventajas, aún mayores cuando el grupo opera a través de la descentralización. Esta fragmentación de la actividad empresarial (pues los productos y servicios que se colocan en el mercado son producto de la coordinación de tareas entre empresas del mismo grupo y además, estas empresas son las destinatarias últimas de su actividad laboral) determina una obligación conjunta de respeto a los derechos de los trabajadores.

No obstante, doctrina jurisprudencial expuesta en los párrafos precedentes, aún ha admitido un nuevo matiz, en este caso, contenido en la STSJ de Cataluña ํㅜ 1634/2018, de 12 de marzo. Se trata de que la "especial vinculación" puede apreciarse aun en el caso de que empresa principal y subcontrata no integren un mismo grupo empresarial. El supuesto concreto trata de una huelga convocada por las personas trabajadoras de las empresas contratistas de la totalidad del servicio de mantenimiento de averías de Telefónica, quien procedió entonces a asumir de forma directa este servicio, dándose la particularidad de que "la recurrente (Telefónica) no es la empresa en la que se convocó la huelga ni la empleadora de los trabajadores en huelga, ni forma parte de un grupo empresarial con las empresas". Pues bien, el TSJ de Cataluña entendió que existía una conducta

${ }^{2}$ VICENTE PALACIO, M.A. (2019). Esquirolaje en supuestos de externalización de empresas pertenecientes al mismo grupo empresarial. Revista de Jurisprudencia Laboral, Volumen 2/2019. 
atentatoria contra el derecho de los huelguistas a pesar del matiz señalado, incidiéndose en lo siguiente:

(...) los actos vulneradores del derecho de huelga pueden ser realizados por terceros empresarios distintos del titular de la empresa o centro de trabajo en cuyo ámbito se produce la huelga, si tales empresarios tienen una especial vinculación con aquel, como sucede en nuestro caso, en el que los trabajadores de las empresas subcontratadas, prestan servicios para Telefónica España, S.A.U. y tal vulneración se produce mediante los actos del empresario principal que sustituye a los trabajadores huelguistas pertenecientes a las empresas colaboradoras contratadas por Telefónica, en cuanto a parte de sus tareas o funciones, con la asunción de las mismas por parte de personal adscrito de modo directo a aquélla, no tratándose de servicios mínimos (...). $\ldots / \ldots$

(...) No cabe alegar por la recurrente la inexistencia de relación laboral con los trabajadores huelguistas para apelar a la falta de responsabilidad en el ejercicio de su derecho de huelga pues, dado que el ejercicio del citado derecho, se ha de proyectar de manera principal sobre la actividad de la empresa principal, cualquier actuación que pudiera desarrollar para neutralizar el ejercicio del derecho de huelga, vulneraría este derecho, como acontece en el caso de autos.

\section{Un nuevo tipo: el "esquirolaje tecnológico"}

\section{Surgimiento del concepto en la jurisprudencia y significado del mismo}

El concepto de "esquirolaje tecnológico" viene delimitado, entre otras resoluciones, en sentencias de 11 de junio de 2012 (recurso de casación 110/2011) y 5 de diciembre de 2012 (recurso de casación 265/2011). Los ejemplos más habituales de esta casuística están en las huelgas que tienen incidencia en retransmisiones de televisión o radio, en las cuales, la prestación de trabajo de los huelguistas es sustituida por grabaciones efectuadas con anterioridad y que permiten la transmisión sin intervención de persona alguna ${ }^{3}$.

En este sentido, el Tribunal Supremo, tras haber variado el criterio que mantuvo en los primeros años que entró a conocer esta modalidad de esquirolaje, viene estableciendo que no sólo

${ }^{3}$ GARCÍA-PERROTE ESCARTÍN, I. y MERCADER UGUINA, J., "Los límites de la sustitución virtual de trabajadores y del recurso a procesos de descentralización durante la huelga en la doctrina reciente del Tribunal Constitucional y del Tribunal Supremo", op. cit., páginas 1 y 2. 
se lesiona el derecho de huelga en el supuesto de que se utilicen medios humanos para la sustitución de los trabajadores huelguistas, sino que también se lesiona este derecho cuando tal sustitución se produce mediante la utilización, por el empresario, de medios mecánicos o tecnológicos que habitualmente no utiliza, con el objeto de mantener su actividad, puesto que con ello priva materialmente a los trabajadores de su derecho fundamental, y se vacía su contenido esencial ${ }^{4}$. Por tanto, puede concluirse que el "esquirolaje tecnológico" es contrario a Derecho por tratarse de un medio que permite al empresario mantener su producción durante el desarrollo de la huelga sin necesidad de utilizar mano de obra.

\section{Posicionamientos del Tribunal Supremo en los periodos 2000-2005 y 2006-2012}

Antes de abordar las sentencias más recientes, sería necesario distinguir dos períodos en los que el TS trató de forma desigual el problema. En el primero de los períodos, el que abarca del año 2000 a 2005, se consideró que el esquirolaje tecnológico no vulneraba el derecho de huelga.

Es destacable la STS de 4 de julio del año 2000, que afirmó de forma taxativa que: "no hay precepto alguno que prohíba al empresario usar los medios tecnológicos de los que habitualmente dispone en la empresa, para atenuar las consecuencias de la huelga". Por su parte, la STS de 9 de diciembre de 2003 reitera el razonamiento anterior bajo la siguiente fundamentación: "es de significar que si la empresa se ve forzada en virtud de la huelga declarada en su ámbito a la paralización de su actividad normal y sólo puede emitir el $50 \%$ de los informativos y los espacios gratuitos de propaganda electoral establecidos por la Junta Electoral (la huelga coincidió con la campaña de elecciones catalanas), no cabe, en buena lógica jurídica, admitir que viole la esencia del derecho fundamental de huelga al ocupar el resto del tiempo de esta última con material propagandístico, ya enlatado con anterioridad, y para cuya emisión solo se precisa pulsar un botón".

En el segundo período, de 2006 a 2012, la situación cambia, motivada por las sentencias del TC número 183/2006 y 191/2006, de 19 de junio. En las citadas resoluciones, se entiende que, con la emisión en horas habituales de emisión de esos programas pregrabados:

(...) se persigue (...) la no interrupción del servicio de la radiodifusión sonora y de la televisión, con lo que se priva de esta forma de repercusión apreciable a la huelga, substrayéndole su virtualidad como medio de presión y de inequívoca exteriorización de los efectos del paro laboral efectivamente producido mediante la exigencia de una apariencia de normalidad del servicio, contraria, como ya hemos señalado, al derecho de huelga.

La STS de 5 de diciembre de 2012, llega aún más lejos al afirmar que la emisión de forma automática de información y publicidad preprogramada vulnera el derecho de huelga aunque no se utilicen trabajadores para ello. En ambas sentencias, se pone de manifiesto que no sólo en el

4LÓPEZ-TAMÉS IGLESIAS, R., "Significativos cercanos pronunciamientos sobre la huelga”, op. cit., página 5. 
supuesto de que se utilicen medios humanos para la realización de actividades que exceden de los servicios decretados como esenciales, se lesiona el derecho de huelga, sino que también se lesiona este derecho cuando una empresa del sector de radiodifusión sonora y televisión emite programación o publicidad por medios automáticos, siquiera cuando sea mediante la utilización de medios mecánicos o tecnológicos. No cabe el uso de las prerrogativas empresariales, aún amparadas en la libertad de empresa, para impedir la eficacia del derecho de huelga, y ello por la propia naturaleza de este derecho y también del de libertad de empresa que no incorpora a su contenido "facultades de reacción frente al paro" ${ }^{\prime \prime}$.

\section{Análisis pormenorizado de la STC de 2/02/2017 y posteriores pronunciamientos}

La STC no 17/2017, de 2 de febrero, ha sido una de las resoluciones con mayor repercusión en los últimos años. La valoración que hace de la actuación empresarial llevada a cabo durante el desarrollo de una huelga, así como del empleo de medios tecnológicos en ese contexto, generó una importante controversia en el ámbito sindical y abrió un debate jurídico sobre el alcance del "esquirolaje tecnológico" entre laboralistas partidarios y detractores de este pronunciamiento del TC. Por ello, se hace preciso detenernos a estudiar con detalle las cuestiones más relevantes de esta sentencia, tal como haremos en los párrafos siguientes.

Los antecedentes de este proceso datan del año 2010, cuando la cadena autonómica de televisión Telemadrid adoptó varias medidas encaminadas a que una huelga impidiese la emisión del partido de la Champions League de fútbol entre el Valencia Club de Fútbol y el Manchester United. Concretamente, el día 29 de septiembre a las 20:45h, llegó a los estudios de Telemadrid la señal del referido partido desde el estadio de fútbol de Mestalla (Valencia) y sin locución.

Ese día, sólo había dos trabajadores que no secundaron la huelga en esta cadena, entre ellos el locutor. La señal llegó a Telemadrid por el servicio del otro trabajador que prestaba servicios en control central y que tenía por funciones, entre otras, conmutar señales. Una vez recibida la señal, ésta fue devuelta automáticamente a control central desde donde se envió a grafismo. Allí el coordinador utilizó una máquina de uso habitual en grafismo e insertó en la misma la "mosca" (logotipo de la cadena en una esquina del plano) con el símbolo de Telemadrid6.

En primera instancia, se determinó que la conducta de la empresa no constituía una vulneración del derecho fundamental de huelga. Posteriormente, previa inadmisión de recurso de casación para la unificación de doctrina, el proceso llegó al TC, quien desestimó el amparo solicitado en base a la siguiente fundamentación:

No hay duda de que la libertad del empresario, por lo que respecta a sus facultades de organización y dirección de los trabajadores, queda restringida por el ejercicio del derecho de huelga, mas no hay

\footnotetext{
${ }^{5}$ LÓPEZ-TAMÉS IGLESIAS, R., "Significativos cercanos pronunciamientos sobre la huelga", op. cit., páginas 7 y 8.

${ }^{6}$ SÁNZ PÉREZ, A., "El poco conocido caso de las máquinas que impidieron hacer huelga", Revista Aranzadi Doctrinal núm. 8/2017, páginas 1 y 2 .
} 
precepto alguno que, durante este ejercicio, prohíba al empresario usar los medios técnicos de los que habitualmente dispone en la empresa para mantener su actividad. Una actividad que, como se ha dicho, es inherente a la lesividad del ejercicio de la huelga e instrumental al ejercicio del derecho al trabajo de aquellos trabajadores que han decidido no sumarse a la misma. De otra parte, exigir al empresario que no utilice medios técnicos con los que cuenta en la empresa supone imponer al empresario una conducta de colaboración en la huelga no prevista legalmente. La utilización de medios ya existentes en la empresa es compatible con el derecho de huelga y no puede extenderse, por vía analógica, a este supuesto la prohibición prevista en el art. 6.5 del Real Decreto-ley 17/1977, que se refiere al empleo de los recursos humanos en la empresa, pero no a la utilización de sus recursos materiales y tecnológicos.

$$
\ldots / \ldots
$$

La efectividad del ejercicio del derecho de huelga no demanda del empresario una conducta dirigida a no utilizar los medios técnicos con los que cuenta en la empresa o a abstenerse de realizar una actividad productiva que pueda comprometer el logro de los objetivos de la huelga, al igual que no obliga a los restantes trabajadores a contribuir al éxito de la protesta, y ello porque lo que garantiza la Constitución es el derecho a realizar la huelga, no el resultado o el éxito de la misma".

Además de lo anterior, es preciso destacar la contundencia del Voto Particular formulado por el Magistrado Valdés Dal-Ré (y al que se adhirieron la Vicepresidenta, Adela Asua, y el Magistrado Juan Antonio Xiol), el cual se muestra frontalmente en desacuerdo con la fundamentación contenida en la sentencia. Este VP trata de reformular qué comportamientos son ilícitos en caso de sustitución interna y rectificar la calificación jurídica de la intervención de los trabajadores no huelguistas que participaron en la retransmisión del evento deportivo. Para ello, expone lo siguiente:

Conforme puede deducirse sin el menor esfuerzo intelectual, la doctrina establecida por las resoluciones calificadas como de referencia, desde la vertiente constitucional, en materia de lesión del derecho de huelga en supuestos de sustitución interna de trabajadores huelguistas por quienes no se sumaron a la huelga y que la presente Sentencia olvida reproducir, formulan una y la misma idea, de sencillo enunciado. En efecto, lo que ambos pronunciamientos sostienen es la ilicitud de aquella medida 
empresarial que, para paliar o minimizar los efectos del ejercicio del constitucional derecho de huelga, encomienda la realización de funciones propias de trabajadores en huelga a trabajadores no huelguistas de un nivel profesional superior al de aquellos.

$$
\ldots / \ldots
$$

(...) la retransmisión del evento deportivo el día de huelga se articuló e instrumentó mediante la actividad laboral de un trabajador no huelguista cuya categoría excedía con creces la de los trabajadores que optaron por secundar la huelga. $O$ por enunciar la idea en el lenguaje de las SSTC 123/1992 y 33/2011, eludido u ocultado por la presente Sentencia, la sustitución de los trabajadores en huelga se efectuó por otros de superior nivel profesional, medida ésta que tacha de irregular e ilícita la sustitución interna $y$, por lo mismo, lesiona el constitucional derecho de huelga".

Posteriormente, el TS en su sentencia de 13 de julio de 2017 (rec. núm. 25/2017, caso Indra y Vodafone), acogió la doctrina constitucional analizada. El Alto Tribunal descartó que existiera vulneración del derecho de huelga en supuesto de hecho de una empresa principal (Vodafone) que, habitualmente, recurría a varios subcontratistas (entre ellos, Indra) para la prestación del servicio de atención telefónica y averías. En el caso analizado, para garantizar dicho servicio, se utilizaba un dispositivo automático que distribuía entre los restantes contratistas las llamadas cuando tenían lugar picos de demanda. El dispositivo en cuestión se basaba en una aplicación cuyo funcionamiento era el siguiente:

(...) conjuga, mediante el correspondiente algoritmo, la distribución de la carga de trabajo entre sus subcontratistas, mediante una aplicación, que activa un dispositivo objetivo, que cohonesta previsiones de llamadas, respuesta a los picos de demanda y al tiempo de recuperación de llamadas, de manera que, si se producen retrasos relevantes, se distribuye a otros proveedores.

En este contexto, se declara una huelga en una de la empresa subcontratista Indra. No obstante, durante el desarrollo de la huelga, la referida aplicación informática efectúa un desvío al resto de empresas subcontratistas de la totalidad de los encargos de atención al cliente. Se dio la controversia de que, ante supuestos parecidos, pero sin el componente tecnológico, el propio TS había resuelto declarando la vulneración del derecho fundamental. Sin embargo, en esta ocasión, el Tribunal Supremo llega a una solución diferente basándose en que "no ha quedado acreditado que las empresas activasen estrategia o tecnología específica para boicotear la huelga. En todo caso, la doctrina de la STCo 17/2017 de 2 febrero (Telemadrid) aleja la sombra de la aludida vulneración". 
Consecuente, el TS vino a reafirmar la idea que había expuesto el TC meses antes, esto es, que no puede exigirse al empresario que no utilice medios técnicos con los que cuenta en la empresa, pues ello supone imponerle una conducta de colaboración en la huelga no prevista legalmente: "(...) la protección constitucional del derecho de huelga impone limitaciones al empresario pero no le obliga, ni a él ni a los empleados que deciden ejercer su derecho a trabajar, a contribuir al éxito de la protesta".

\section{DISCUSIÓN Y CONCLUSIONES}

La jurisprudencia más reciente viene poniendo de manifiesto la necesidad de dotar de contenido a nuestro ordenamiento jurídico para que éste pueda velar con todas las garantías por el correcto ejercicio de la huelga en contextos muy diferentes a los que existían cuando fue aprobada la Constitución hace cuarenta años.

Extraer un análisis de la regulación actual del derecho de huelga en nuestro ordenamiento jurídico y, en consecuencia, sobre el esquirolaje, implica necesariamente hacer una reflexión sobre la carencia de preceptos normativos referidos a esta materia.

Asimismo, lo anterior va ineludiblemente vinculado al papel preponderante de los criterios interpretativos que el TC y el TS han venido introduciendo periódicamente, llegando a disponer a día de hoy de una casuística cualitativamente amplia, aunque sujeta a una permanente evolución.

Varias conclusiones subyacen de lo anterior:

Primera. El esquirolaje externo es único tipo que viene expresamente prohibido en la normativa vigente. No obstante, el alcance de esta prohibición es interpretada de forma más extensa de lo que dispone la norma en un sentido literal.

Segunda. En este sentido, la jurisprudencia ha venido eliminando espacios inmunes a la vigencia del derecho de huelga en supuestos de externalización productiva. No en vano, es evidente que mediante la subcontratación de actividades, puede verse afectada la efectividad de este derecho fundamental, no sólo por la actuación del contratista sino también por la del empresario principal.

Tercera. Además, en los procesos de descentralización productiva, se considera esquirolaje externo no sólo la sustitución de huelguistas por trabajadores que fueran ajenos a la empresa en un momento previo al inicio de la huelga, sino que también abarca su sustitución por trabajadores pertenecientes a otros centros de la empresa e, incluso, a empresas subcontratistas que guarden una "especial vinculación" con la empresa cliente.

Cuarta. En el caso del "esquirolaje tecnológico", al igual que sucedió anteriormente con el esquirolaje interno, la jurisprudencia ha pasado de admitir la validez del mismo en una primera etapa, a limitar su práctica de manera ciertamente restrictiva en los siguientes años. 
Quinta. No obstante, la STC 17/2017, de 2 de febrero, vuelve a flexibilizar la sustitución del servicio correspondiente a trabajadores en huelga mediante el empleo de instrumentos tecnológicos en determinados supuestos. El argumento fundamental empleado es que "La efectividad del ejercicio del derecho de huelga no demanda del empresario una conducta dirigida a no utilizar los medios técnicos con los que cuenta en la empresa", lo cual es incurrir en una valoración muy controvertida de la norma. Por ello, esta sentencia ha sido enormemente relevante, generando corrientes de opinión a favor y en contra de su fundamentación. No obstante, el criterio del Tribunal Constitucional ha sido reafirmado con posterioridad por el Tribunal Supremo en su sentencia de 13 de julio de 2017 (rec. núm. 25/2017, caso Indra y Vodafone), dotándole de mayor solidez aún.

\section{REFERENCIAS}

Escribano Gutiérrez, J. (2012). El esquirolaje interno como ataque al derecho fundamental de huelga. Temas laborales (116), 205-2014.

García Jiménez, M. (2019). Revolución Industrial 4.0, sociedad cognitiva y relaciones laborales. Revista de Trabajo y Seguridad Social (1), 147-182.

García-Perrote Escartín, I. y Mercader Uguina, J. (2017). Los límites de la sustitución virtual de trabajadores y del recurso a procesos de descentralización durante la huelga en la doctrina reciente del Tribunal Constitucional y del Tribunal Supremo. Revista de Información Laboral (6/2017).

López-Tamés Iglesias, R. (2014). Significativos cercanos pronunciamientos sobre la huelga. Revista Española de Derecho del Trabajo (164), 115-141.

Montoya Melgar, A. (2020). Derecho del Trabajo. (41a ed.). Editorial Tecnos.

Ortega Lozano, P.G. (2021). Derecho de huelga en estructuras empresariales complejas. Revista General de Derecho del Trabajo y de la Seguridad Social (58).

Palomeque López, M. y Álvarez de la Rosa, M. (2017). Derecho del Trabajo. (25aㅡ ed.). Editorial Universitaria Ramón Areces.

Sala Franco, T. (2020). Derecho sindical. (3 $3^{\mathrm{a}}$ ed.). Editorial Tirant Lo Blanch.

Sanz Pérez, A. (2017). El poco conocido caso de las máquinas que impidieron hacer huelga. Revista Aranzadi Doctrinal (8/2017), 157-165.

Vicente Palacio, M.A. (2019). Esquirolaje en supuestos de externalización de empresas pertenecientes al mismo grupo empresarial. Revista de Jurisprudencia Laboral (2/2019). 


\section{ANEXO: SENTENCIAS Y RESOLUCIONES ANALIZADAS}

\section{1.- Sentencias del Tribunal Constitucional}

\begin{tabular}{|c|c|}
\hline -STC 11/1981, de 8 de abril & -STC 51/1986, de 24 de abril \\
\hline -STC 53/1986, de 5 de mayo & -STC 27/1989, de 3 de febrero \\
\hline -STC 43/1990, de 15 de marzo & -STC 123/1992, de 28 de septiembre \\
\hline -STC 148/1993, de 29 de abril & -STC 123/1998, de 15 de junio \\
\hline -STC 183/2006, de 19 de junio & -STC $184 / 2006$, de 19 de junio \\
\hline -STC 191/2006, de 19 de junio & -STC 193/2006, de 19 de junio \\
\hline -STC 75/2010, de 19 de octubre & -STC 33/2011, de 28 de marzo \\
\hline -STC 104/2011, de 20 de junio & -STC 17/2017, de 2 de febrero \\
\hline
\end{tabular}

\section{2.- Sentencias del Tribunal Supremo}

\begin{tabular}{|ll|}
\hline -STS de 23 de octubre de 1989 & -STS de 24 de octubre de 1989 \\
\hline -STS de 8 de mayo de 1995 & -STS de 18 de julio de 1997 \\
\hline -STS de 4 de julio de 2000 & -STS de 9 de diciembre de 2003 \\
\hline -STS de 8 de junio de 2011 & -STS de 11 de junio de 2012 \\
\hline -STS de 5 de diciembre de 2012 & -STS de 6 de junio de 2014 \\
\hline -STS de 11 de febrero de 2015 & -STS de 20 de abril de 2015 \\
\hline -STS de 18 de marzo de 2016 & -STS de 20 de julio de 2016 \\
\hline -STS de 16 de noviembre de 2016 & \\
\hline
\end{tabular}

\section{3.- Sentencias de la Audiencia Nacional}

-SAN de 12 de junio de $2014 \quad$-SAN de 29 de octubre de 2017

\section{4.- Sentencias de los Tribunales Superiores de Justicia}

\begin{tabular}{|ll|}
\hline -STSJ de Madrid de 20 de julio de 1991 & -STSJ de Navarra de 28 de abril de 1995 \\
\hline -STSJ de Extremadura de 30 de noviembre de 1998 -STSJ de País Vasco de 4 de julio de 2000 \\
\hline -STSJ de Navarra de 30 de abril de 2001 & -STSJ de Cataluña de 5 de julio de 2002 \\
\hline -STSJ de Galicia de 27 de septiembre de 2003 & -STSJ de Cataluña de 28 de septiembre de 2011 \\
\hline -STSJ de Madrid de 23 de enero de 2012 & -STSJ de Andalucía de 10 de octubre de 2013 \\
\hline -STSJ de Extremadura de 29 de abril de 2014 & -STSJ de Murcia de 10 de septiembre de 2014 \\
\hline -STSJ de Cataluña de 14 de abril de 2015 & \\
\hline
\end{tabular}

